\title{
Thyroidectomy for Massive Goiter Weighing more than 500 Grams. Technical Difficulties, Complications and Management. Review
}

\author{
Norman Oneil Machado \\ Department of Surgery, Sultan Qaboos University Hospital, \\ Muscat, Oman \\ E-mail: oneilnorman@gmail.com \\ Received December 2, 2010; revised April 4, 2011; accepted May 31, 2011
}

\begin{abstract}
Background: Multinodular goiter is a relatively common thyroid disorder with a marked female preponderance. Most of these goiters weigh less than 100 grams with those weighing more than 500 grams being exceptional. The massively expanding goiter due to the strategic anatomic location of thyroid gland, in addition to being cosmetically disfiguring can seriously compromise the patency of the trachea and oesophagus. Thyroidectomy for such goiters is a surgical challenge due to the possible association of tracheomalacia, retrosternal extension, skin involvement and the difficulty in intubation and dissection of the thyroid gland due to distorted and displaced anatomy. Material and methods: While presenting 2 patients who underwent thyroidectomy for glands weighing more than 500 grams, the literature is reviewed to analyze the technical difficulties and approach in such patients and the frequently encountered complications in them and their management. Results: A review of the literature revealed an additional 7 cases of patients who had undergone thyroidectomy for glands weighing more than 500 grams. Massively enlarged goiter was often associated with tracheomalacia, tracheal stenosis and retrosternal extension. Difficulty during surgery was most often encountered in establishing the airway and in exposure of the gland particularly when the skin was involved. The predominant postoperative complications were related to respiratory distress as a consequence of tracheomalacia and tracheal stenosis. Conclusion: In spite of the technical challenge related to the airway, and thyroidectomy, surgery continues to be the best option in experienced hands due to its distinct advantage of its immediate effect and complete resolution of compressive symptoms.
\end{abstract}

Keywords: Thyroidectomy, Massive Goiters, Tracheomalacia, Retrosternal Goiter

\section{Introduction}

It is estimated that nodular goiter affects $5 \%$ of the general population [1]. The usual goiter growth ratio is estimated at 10 to $20 \%$ per year, though high individual variability in the clinical course makes it difficult to predict whether the goiter size will remain stable or whether dynamic thyroid growth will lead to its rapid progress warranting surgical intervention [2]. Most of these goiters are of moderate size being less than 100 grams [3]. Glands weighing more than 500 grams are extremely unusual and often result as a consequence of ignorance, neglect, lack of inadequate medical facility, fear of undergoing surgery or due to an unusually rapid growth as in malignancy [4-7]. These patients pose a specific surgical chal- lenge and need to be managed by experienced surgeons. In addition to presenting our experience with 2 cases, the literature is reviewed to analyze the technical difficulties, complications and the approach in managing them.

\section{Case Reports}

\subsection{Case 1}

An 58 year old lady presented with a massively enlarged goiter of more than 8years duration. She had recent history of exertional stridor and neck discomfort and had declined surgery in the past out of fear of surgery. On clinical examination the mass was measuring about $24 \times$ $18 \mathrm{cms}$ involving most of the neck (Figure 1). The lower 
border could not be felt. The complete blood picture, and thyroid function tests were within normal limits. A CT scan revealed a massive goiter compressing the trachea (Figure 2). After an informed consent the patient was posted for total thyroidectomy. Flexible intubation was performed. After adequate extension of the neck supported by sandbag, the neck was explored using a $30 \mathrm{cms}$ incision. After reflecting the subplatysmal skin flaps the thyroid gland was exposed by dividing the strap muscles as there was significant compression of internal jugular vein and carotid vessels and distortion and displacement

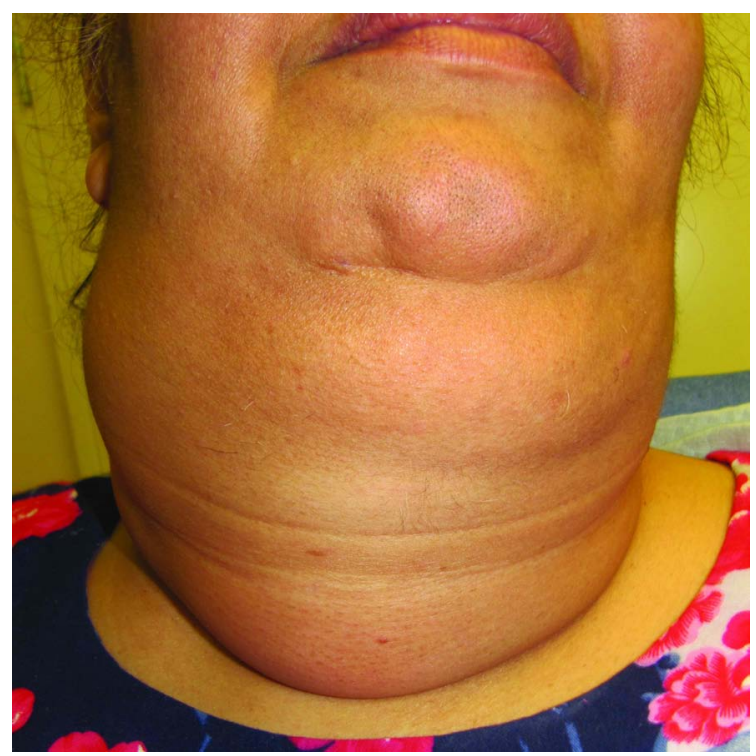

Figure 1. Massive goiter weighing more than 800 grams involving most of the neck.

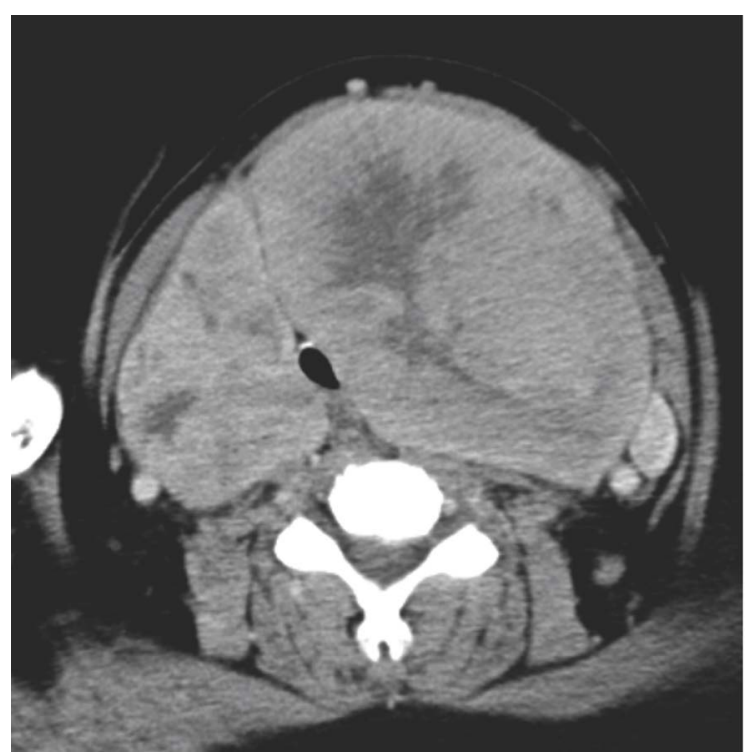

Figure 2. CT scan-transverse section revealing significant compression and deviation to the right of trachea by the massively enlarged goiter. of these structures. The superior pedicle, multiple dilated middle thyroid veins and inferior thyroid vein and branches of inferior thyroid artery were carefully ligated on both sides. The recurrent laryngeal nerve and parathyroids were identified on both sides and preserved. The retrosternal extension of the goiter was delivered into the neck by gentle finger dissection and upward traction in the subcapsular plane. The total blood loss was $180 \mathrm{~mL}$. The tracheal cartilage appeared healthy and the patient was extubated on Table immediately after the surgery. There were no postoperative complications and the patient was discharged on the $4^{\text {th }}$ postoperative day. The histopathology was reported to be multinodular goiter, the total weight of the excised gland being 824 grams. (See Figure 3)

\subsection{Case 2}

A 62 year old lady who was clinically euthyroid presented with progressively enlarging goiter of 10 years duration. The goiter measured $20 \times 16$ and prominent veins in the neck and chest were observed due to retrosternal extension (Figure 4). The complete blood picture and thyroid function tests were within normal limits. CT scan of the neck revealed tracheal compression and retrosternal extension. The patient was posted for total thyroidectomy after an informed consent. The intubation was achieved by direct laryngoscopy. Adequate exposure of the thyroid gland was achieved by sufficient neck extension, division of strap muscles and adequate retraction. After ligating all the vessels carefully and identifying and preserving the recurrent laryngeal nerve and parathyroids on both sides, the retrosternal extension of the goiter was delivered into the neck by gentle finger dissection and traction. The total blood loss was $130 \mathrm{~mL}$ and the patient was extubated on Table at completion of the surgery. The postoperative period was uneventful.

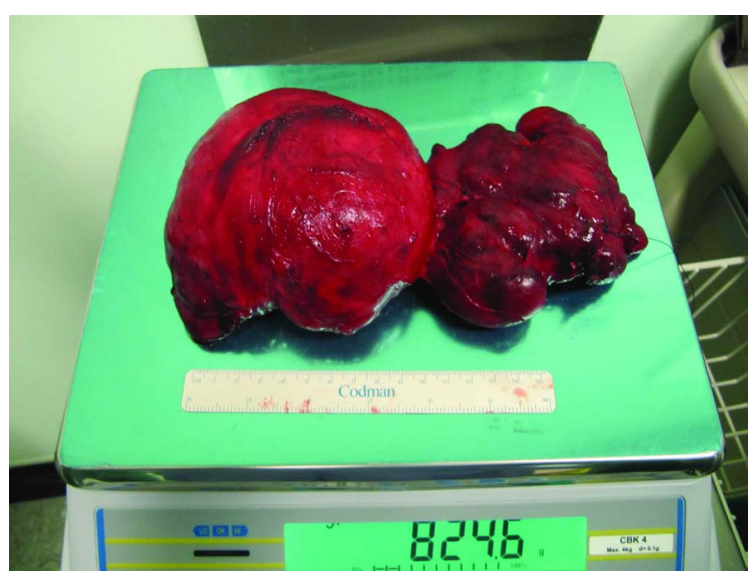

Figure 3. Post total thyroidectomy specimen revealing gland weighing 824 grams. 


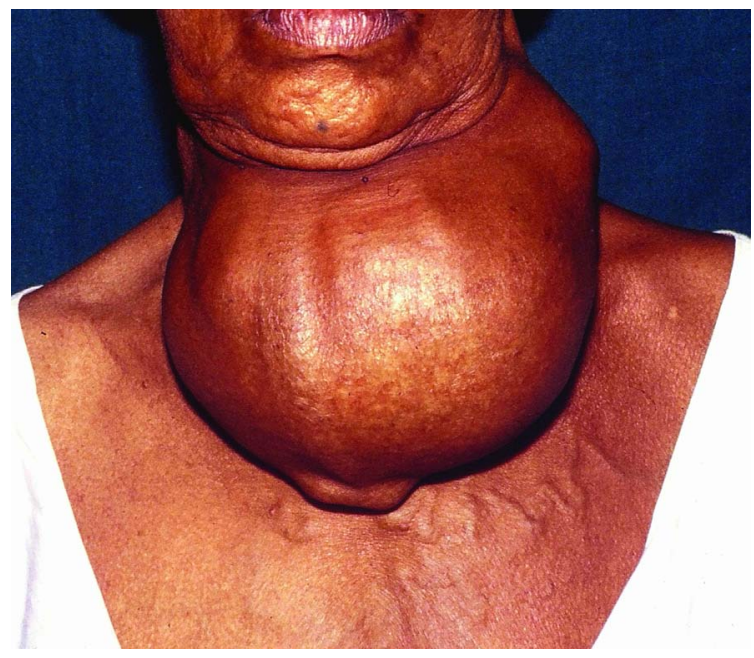

Figure 4. Patient 2-with massively enlarged goiter with retrosternal extension revealing associated dilated jugular and anterior chest veins.

The excised gland weighed 640 grams and was reported to be a multinodular benign goiter.

\section{Discussion}

Thyroidectomy for massively enlarged goiter could be technically challenging particularly when they are more than 500 grams. The specific problems associated with them are difficulty in securing airway, adequate exposure, blood loss, and potential risk of injury to recurrent laryngeal nerve, oesophagus and the parathyroid gland due to distorted and displaced anatomy [4-9]. Moreover there is an increased possible association of tracheomalacia, tracheal compression, retrosternal extension and skin complications due to ulceration or infiltration by the massively enlarged goiter [4-9]. The surgical approach to such cases requires careful preoperative evaluation and planning. Each case is dealt with differently and the technical difficulties both surgical and anaesthetic must be anticipated in order to minimize perioperative morbidity and mortality,

Intubation of these patients could be demanding due to gross tracheal deviation, compression or tracheomalacia and should be anticipated by the anaesthetists in the preanaesthetic assessment [4,6,8-10]. Intubation is usually achieved in these difficult cases by flexible intubation using relatively smaller sized tube (size 4 and above) in case of severe narrowing [4,6,7] (Tables 1 \& 2). Awake intubation using fiberoptics and local anaesthetics has been performed successfully in extremely difficult cases $[4,6,8]$. Another difficult situation is when the stenosis is over a long segment. Successful intubation has been achieved in patients with stenosis extending from the cricoid cartilage to carina by passing an ex- tended length tube (Sheridan, $4 \mathrm{~mm}$-internal diameter-endotracheal tube-Hudson RCI USA, Temecula,CA) through the ste- nosis with the tip at the level of carina [8]. Massively enlarged goiter have also been removed successfully under local anaesthesia (LA), an exceptional case being the removal of a thyroid gland weighing 1.9 $\mathrm{kg}$ [5]. The merits of performing thyroidectomy under LA according to the authour is specially in a rural setting in a developing country where there is frequent shortage of equipment, drugs, trained theater personnel and ward staff [5]. The severe shortage of staff in such countries means that it is not safe to have a patient recovering from GA unsupervised after an operation on the neck [5]. Surgery under LA made it feasible to send these patients immediately back to ward fully conscious and able to communicate [5]. However the obvious risk of performing difficult thyroidectomy under LA is an unforeseen situation of severe bleeding or respiratory distress leaving the patient and surgeon in a vulnerable position.

Thyroidectomy for a massively enlarged goiter requires the neck to be well exposed by adequate extension achieved by placing adequate amount of sandbags under the shoulder $[4,7,8]$. The incision is invariably long extending even up to $40 \mathrm{cms}$ at times [7]. In patients where skin is involved with resulting ulceration as in a malignant goiter, the skin incision will have to be fashioned to include and excise the ulcerated area [4]. After reflecting the subplatysma skin flap adequate exposure is achieved by dividing the strap muscles and if need be the sternomastoid muscle $[4,7,8]$. This ensures safe ligation of the superior pedicle, the middle thyroid vein and branches of inferior thyroid artery. Securing these vessels in this crowded space could be demanding as the internal jugular vein and carotid artery are compressed and displaced by the massively enlarged goiter. The use of harmonic scalpel may facilitate safe and speedy securing of these vessels specially when they are multiple and dilated due to partly obstructed venous outflow as in the presence of retrosternal extension [7]. Of particular concern is also the potential risk of injury to the oesophagus due to gross distortion of the anatomy in patients with retropharyngeal and retroesophageal extension and preoperative insertion of nasogastric tube may serve as a guide to identify it $[7,10]$. The removal of the gland may be facilitated by dividing it at the isthmus after mobilizing one lobe rather than attempting to remove it in toto [7]. The removal of the other half would then be relatively easy due to the space created. Care is taken to preserve the parathyroids and prevent injury to the recurrent laryngeal nerve [3-10]. Use of intraoperative nerve monitoring has been reported to be very useful in these difficult cases [11]. Apart from facilitating navigation through distorted anatomy it may lend itself as a routine adjunct to the gold 
standard of visual nerve identification [11].

Three specific problems that are likely to be associated with massively enlarged goiter is that of skin involvement, tracheomalacia and retrosternal extension [4,6-10]. In one of the reports with extensive involvement of skin two approaches have been employed ${ }^{4}$. In one approach for a patient with a fungating lesion the dissection was initially carried out from the noninvolved side [4]. This allowed access to the goiter on the involved side from within, gradually dissecting the entire mass together with excision of the overlying skin elliptically around it [4]. In another patient with an ulcerated bleeding lesion the line of incision included the entire ulcerated area initially and then deepened to lift the skin flaps at the onset. The thyroid lobe was then mobilised from the involved side progressing on to the side where skin was not involved [4]. The wide excision of the involved skin poses a problem in skin closure. While a small segment of the defect could be closed by mobilizing the adjoining skin, larger defects particularly in a previously irradiated skin may require closure by mobilizing flaps like a deltopectoral flap [4].

Tracheomalacia is an uncommon complication in a patient undergoing thyroidectomy and occurs in 0.1 to $0.5 \%$ [12]. However in patients with massively enlarged goiter the risk is relatively higher $[7,12]$. The major concern is that it may cause life threatening post operative airway obstruction with the recorded mortality of $44 \%$ $[12,13]$. Its mechanical effect usually results from compression by the surrounding goiter leading to softening of the tracheal cartilage $[12,13]$. The trachea may collapse immediately following extubation or as late as 48 hours into the postoperative period. Several technique for identifying tracheomalacia have been advocated [14-17]. A simple and economical method of detecting tracheomalacia on the operating table is at the end of surgery before reversing residual neuromuscular blockade and extubation [14]. After thorough suctioning of the oropharynx, the cuff is deflated [14]. Tracheomalacia would result in tracheal collapse over the tube preventing peritubal leak after cuff deflation [14]. The presence of leak would exclude tracheal collapse [14]. Intra-operative inspection of the trachea by the surgeon also may reveal tracheomalacia [7]. In such a situation in addition to surgical re-enforcement, the patient may need to be intubated in early postoperative period.

In patients at risk of developing upper airway obstruction following thyroidectomy the choice lies between prophylactic endotracheal intubation and tracheostomy $[13,17]$. Endotracheal intubation is favoured by many due to its less morbidity [13]. However tracheostomy may be needed in situation were the trachea collapses post tumour removal [7]. Tracheostomy has been reported to have been performed in 6\% (59/964) of patients following thyroidectomies [18], the indication primarily being intraoperative tracheal deformity with narrowing (more than $50 \%$ ) of tracheal circumference on radiology and gland adherence to the tracheal wall or tracheomalacia $[12,18]$.

A massively enlarged goiter is often associated with mediastinal extension giving rise to additional challenges to the surgeon $[7,10]$. These include difficult intubation, incision and approach to the tumour, tracheomalacia , possibility of sternotomy and problem of wound healing. However, majority of the retrosternal goiters are secondary, having extended from the neck into the superior mediastinum. These can be removed by transcervical approach by finger dissection and upward traction of the cervical thyroid through the subcapsular plane after securing its blood supply initially in the neck $[7,8,10,19]$. Extracervical approach like median sternotomy or lateral thorocotomy is reserved for cases with previous cervical thyroidectomy, invasive carcinoma, ectopic primary goiter and goiter extending into the posterior mediastinum well beyond the aortic arch and may need the services of cardiothoracic surgeons [19].

Patients with large goiters may functionally be hypothyroid, hyperthyroid or euthyroid. The commonly encountered symptoms in patients with massively enlarged goiters are dysphagia and dypsnea due to oesophageal and tracheal compression [3,4,7,9,10]. These lesions could be benign or malignant and the pathological nature of the goiter is established by fine needle aspiration cytology .Computerized tomography scan is an useful imaging modality especially in complicated massive goiter, in delineating the degree of tracheal compression and deviation and establishing the extent of retrosternal extension $[7,10,19]$. Most of these patients with massively enlarged goiters are managed by total thyroidectomy [20]. Total thyroidectomy is preferred as 10 to $20 \%$ recurrence has been observed in patients with lesser surgery [20]. In such patients postoperative thyroxine may fail to prevent recurrence suggesting the glands are becoming increasingly autonomous during growth [20]. Moreover surgery for recurrent goiter carries a 10 fold higher complication rate with complications such as permanent hypoparathyroidism (3.4\%) and recurrent laryngeal nerve palsy $(8 \%)[3,20]$. However most authours conclude that surgery is the best management strategy in generally healthy patients with large goiters [3,4-9]. The most important advantage of thyroid surgery for massively enlarged goiter being its immediate effect and complete resolution of obstructive symptoms [3,4-9].

\section{Literature Review}

A medline literature search of English language articles was performed using terms massively enlarged goiter or 
large goiter. All articles that reported thyroidectomy for goiters weighing more than 500grams were reviewed including those that were discovered in references in the article uncovered during the search. The studies with incomplete data particularly in relation to the weight were rejected. Since 1970 a total of 7 cases of patients undergoing thyroidectomy for glands weighing in excess of 500 grams were identified [4-9]. Interestingly all the patients including the 2 in our study were female patients. The demographic details and presentation are noted in Table 1. Tracheal compression was seen in 2 patients and tracheomalacia and tracheal stenosis was seen in one patient each. Skin involvement was seen in 2 patients (fungating lesion and large bleeding ulcer) both related to underlying thyroid malignancy (papillary carcinoma and medullary carcinoma of thyroid) (Table 1). The intubation was achieved by direct laryngoscopy (4 patients), flexible intubation (3 patients), awake intubation (1 patient) and one patient underwent thyroidectomy under local anaesthesia. The maximum length of the incision was $40 \mathrm{cms}$ (range 28 to $40 \mathrm{cms}$ in cases were it was mentioned) (Table 2). In 2 patients where the skin

Table 1. Literature Review - Thyroidectomy for glands weighing more than $\mathbf{5 0 0}$ grams Demographic details/clinical features.

\begin{tabular}{|c|c|c|c|c|c|c|c|c|c|c|}
\hline Author-year & $\begin{array}{c}\text { No of } \\
\text { pts }\end{array}$ & Age yrs & Sex M:F & $\begin{array}{c}\text { Size of } \\
\text { gland cms }\end{array}$ & $\begin{array}{l}\text { Weight of } \\
\text { gland gms }\end{array}$ & Symp & Retrost Exten & $\begin{array}{l}\text { Tracheal } \\
\text { deformity }\end{array}$ & Skin Inv. & $\begin{array}{c}\text { Thyroid } \\
\text { pathology }\end{array}$ \\
\hline Present & 2 & 58 & $0: 1$ & $24 \times 18$ & 824 & Dys/Ndis & $1 \mathrm{~cm}$ & Tcom & Nil & MNG \\
\hline study & & 62 & $0: 1$ & $20 \times 16$ & 640 & Dys/ Ndis & $2 \mathrm{cms}$ & Tcom & Nil & MNG \\
\hline $\begin{array}{l}\text { Irfan et } a l^{7} \\
\quad 2010\end{array}$ & 1 & 30 & $0: 1$ & $30 \times 15$ & 915 & Dys Dysph toxic & +Upto AA & $\begin{array}{c}\text { Tmal-1 } \\
\text { Size-6mm }\end{array}$ & no & $\begin{array}{l}\text { Colloid } \\
\text { goiter }\end{array}$ \\
\hline $\begin{array}{c}\text { Dere } K^{6} \\
2008\end{array}$ & 1 & 19 & $0: 1$ & $36 \times 15$ & 1235 & cretin & no & no & no & MNG \\
\hline $\begin{array}{l}\text { Eloy JA }^{8} \\
2007\end{array}$ & 1 & 46 & $0: 1$ & $20 \times 9$ & 610 & Dys Dysph & +upto carina & Tsten > 90\% & no & MNG \\
\hline $\begin{array}{c}\text { Harjit } \mathrm{K}^{4} \\
2005\end{array}$ & 2 & $\begin{array}{l}52 \\
66\end{array}$ & $0: 2$ & $\begin{array}{c}14 \times 7 \\
19 \times 25\end{array}$ & $\begin{array}{c}? \\
1100\end{array}$ & $\begin{array}{c}\text { Previous } \\
\text { Thyrect + RT } \\
\text { (2pts) }\end{array}$ & no & no & $\begin{array}{l}\text { fungating } \\
\text { ulcerating }\end{array}$ & $\begin{array}{l}\text { Papillary ca } \\
\text { Medullary ca }\end{array}$ \\
\hline $\begin{array}{l}\text { Hodges } \mathrm{AM}^{5} \\
2005\end{array}$ & 1 & 30 & $0: 1$ & $?$ & 1900 & $\begin{array}{l}\text { Pain } \\
\text { Ndis }\end{array}$ & no & no & no & MNG \\
\hline $\begin{array}{l}\text { Holden MP } \\
\text { et al }{ }^{9} 1972\end{array}$ & 1 & 38 & $0: 1$ & $?$ & 800 & $\begin{array}{l}\text { Hypertension-comp AA } \\
\text { Previous Thyrect }\end{array}$ & $\begin{array}{c}+ \\
\text { Upto AA }\end{array}$ & no & no & $\begin{array}{l}\text { Colloid } \\
\text { goiter }\end{array}$ \\
\hline Total & 9 & $\begin{array}{c}(30-66) \\
\text { Mean-44.5 }\end{array}$ & $0: 9$ & $36 \times 25$ & $\begin{array}{c}(640 \times \\
1900) \\
\text { Mean-823 } \\
\end{array}$ & $\begin{array}{c}\text { Pain/Ndis-3 } \\
\text { Dys-4 } \\
\text { Dysph-2 } \\
\end{array}$ & 5 & $\begin{array}{l}\text { Tcom-2 } \\
\text { Tsten-1 } \\
\text { Tmal-1 } \\
\end{array}$ & 2 & $\begin{array}{c}\text { Benign-7 } \\
\text { Malignant-2 }\end{array}$ \\
\hline
\end{tabular}

Rt Ext—retrosternal extension, Dys—dysnea or stridor, Dysph—dysphagia, Ndis—neck discomfort, AA—arch of aorta, Tcom—tracheal compression, Tsten-tracheal stenosis, Tmal-tracheomalacia, thyrect-thyroidectomy

Table 2. Literature review—surgical details.

\begin{tabular}{|c|c|c|c|c|c|c|}
\hline Author-year & $\begin{array}{c}\text { Intubation Technique } \\
\text { Tube size }\end{array}$ & incision & $\begin{array}{c}\text { Division } \\
\text { of Stp or Sm }\end{array}$ & $\begin{array}{c}\text { Use of } \\
\text { harmonic scalpel }\end{array}$ & Blood loss & Complications \\
\hline Present study (2pts) & Flex Int & $36 \mathrm{cms}$ & Stp- yes & No & 180 & nil \\
\hline 2010 & Flex int & $30 \mathrm{cms}$ & Stp- yes & No & 130 & nil \\
\hline Irfan et $a l^{7}$ (2pts) & Flex.int & $40 \mathrm{cms}$ & Stp- yes & + & $?$ & Tracheostomy for \\
\hline 2010 & $6.5 \mathrm{~mm}$ & $?$ & Sm -no & + & $?$ & Tmal \\
\hline $\begin{array}{l}\text { Dere } K^{6} \\
2008\end{array}$ & $\begin{array}{c}\text { DL } \\
5.5 \mathrm{~mm}\end{array}$ & ? & no & no & ? & nil \\
\hline $\begin{array}{l}\text { Eloy JA }{ }^{8} \\
2007\end{array}$ & $\begin{array}{c}\text { DL } \\
\text { 4mm Sheridan tube }\end{array}$ & $?$ & no & no & ? & nil \\
\hline $\begin{array}{l}\text { Harjit } K^{4} \\
2005\end{array}$ & Aw int & Elliptical + Skin excision & no & no & ? & nil \\
\hline $\begin{array}{l}\text { Hodges } \mathrm{AM}^{5} \\
2005\end{array}$ & $\begin{array}{c}\text { LA } \\
0.25 \% \text { lignociane- } \\
\text { Adrenaline-1: } 200,000 \\
\text { Pethedine } \\
\text { ketamine }\end{array}$ & long & $?$ & ? & ? & Oedema of skin flap \\
\hline Total & $\begin{array}{c}\text { GA-8 } \\
\text { LA-1 } \\
\text { DL-4 } \\
\text { Flex int-3 } \\
\text { Aw int-1 }\end{array}$ & $\begin{array}{l}\text { Thorocotomy-1 } \\
\text { Neck incision-8 }\end{array}$ & $\begin{array}{l}\text { Stp- } 3 \\
\text { Sm-1 }\end{array}$ & $\begin{array}{l}\text { Harmonic scal- } \\
\text { pel-1 }\end{array}$ & $\begin{array}{c}(130-180 \mathrm{ml}) \\
\text { Most have not } \\
\text { reported }\end{array}$ & Tracheostomy-1 \\
\hline
\end{tabular}

Flex int—flexible intubation, DL—direct laryngoscopy, Aw int—awake intubation, Stp—strap muscles, Sm—sternomastoid muscle. 
was involved and required excision of involved segment, the skin cover after thyroidectomy was achieved with local advancement flap or deltopectoral flap in one patient each. The goiters were of a benign nature except for 2 cases with malignancy. The mean weight of the gland that was excised was 823 grams (range 640 - 1900 grams). Thyroidectomy was facilitated by the use of harmonic scalpel, division of strap muscles and sternomastoid muscle in some of these patients (Table 2). Four of these patients had retrosternal extension, 3 of them being approached transcervically and one with previous thyroidectomy was approached through right lateral thorocotomy. Tracheostomy had to be performed in one patient with severe tracheomalacia who was initially managed with intubation but failed following extubation; in two other patients tracheostomy was performed because they required prolonged period of postoperative intubation. Interestingly complications including recurrent laryngeal nerve palsy, hypocalcaemia or postoperative haemorrhage was not reported in any patients probably reflecting the special care taken in performing these challenging cases by experienced surgeons.

\section{Conclusions}

Thyroidectomy for a massively enlarged goiter especially when weighing more than 500 grams is technically challenging. Airway management, integrity of adjacent structures as well as anticipating the possible complications should be considered as high priority. Often associated findings in these patients include tracheal compression and tracheomalacia, retrosternal extension, and possible skin involvement. In spite of the technical challenge, surgery continues to be the best option particularly in experienced hands due to its distinct advantage of immediate effect and complete resolution of compressive symptoms.

\section{References}

[1] T. A. Day, A. Chu and K.G. Hoang, "Multinodular Goiter," Otolaryngologic Clinics of North American, Vol. 36, No. 1, 2003, pp. 35-54. doi:10.1016/S0030-6665(02)00157-3

[2] A. Berghout, W. M. Wersinga, H. A. Drexhage, N. J. Smits and J. L. Touber, "Comparison of Placebo with L-Thyroxine Alone or with Carbimazole for Treatment of Sporadic Non Toxic Goiter," Lancet, Vol. 336, No. 8709,1990, pp. 193-197. doi:10.1016/0140-6736(90)91730-X

[3] K. R. Gardiner and C. F. Russell, "Thyroidectomy for Large Multinodular Colloid Goitre,” Journal of the Royal College of Surgeons of Edinburgh, Vol. 40, No. 6, 1995, pp. 367-370.
[4] K. D. Harjit and A. N. Hisham, "Large Fungating Thyroid Cancers. A Unique Surgical Challenge,” Asian Journal of Surgery, Vol. 28, No. 1, 2005, pp. 48-51. doi:10.1016/S1015-9584(09)60259-1

[5] A. M. Hodges, "Excision of a $1.9 \mathrm{Kg}$ Goitre under Local Anaesthetic,” Tropical Doctor, Vol. 35, No. 1, 2005, p. 43. doi:10.1016/S1015-9584(09)60259-1

[6] K. Dere, E. Teksoz, H. Sen , M. E. Orhan, S. Ozkan and G. Dagli, "Anaesthesia in a Child with Massive Thyroid Enlargement,” Paediatric Anaesthesia, Vol. 18, No. 8, 2008, pp. 797-798. doi:10.1111/j.1460-9592.2008.02547.x

[7] M. Irfan, W. S. Jiham and H. Shahid, "Massive Goiter with Retrosternal Extension Encasing Trachea and Oesophagus," Medical journal of Malaysia, Vol. 65. No. 1, 2010, pp. 85-86.

[8] J. A. Eloy, S. Omerhodzic, S. Yuan, E. M. Genden and A. S. Jacobson, "Extended Tracheal Stenosis Secondary to a Massive Substernal Goiter,” Thyroid, Vol. 17, No. 9, 2007, pp. 899-900. doi:10.1089/thy.2006.0291

[9] M. P. Holden, G. H. Wooler and M. I. Ionescu, "Massive Retrosternal Goitre Presenting with Hypertension,” Thorax, Vol. 27, No. 6, 1972, pp. 772-774. doi:10.1136/thx.27.6.772

[10] D. P. Martin-Hirsch and F. J. Lannigan, “The Management of Benign Thyroid Goiter Causing Tracheo-Oesophageal Embarrassment," Journal of Laryngology \& Otology, Vol. 109, No. 9, 1995,pp. 892-894. doi:10.1017/S0022215100131615

[11] H. Dralle, C. Sekulla, K. Lorenz, M. Brauckhoff and A. Machens, "German IONM Study Group. Intraoperative Monitoring of the Recurrent Laryngeal Nerve in Thyroid Surgery,” World Journal of Surgery, Vol. 32, No. 7, 2008, pp. 1358-1366. doi:10.1007/s00268-008-9483-2

[12] W. E. Green, W. H. Shepperd, H. M. Stevensen and W. Wilson, “Tracheal Collapse after Thyroidectomy," British Journal of Surgery, Vol. 66, No. 8, 1979, pp. 554-557. doi:10.1007/s00268-008-9483-2

[13] N. T. Hamilton, C. Christophi, J. B. Swann and G. J. Robinson, "Endotracheal Intubation Following Thyroidectomy," The Australian and New Zealand journal of surgery, Vol. 57, No. 5, 1987, pp. 295-298. doi:10.1111/j.1445-2197.1987.tb01360.x

[14] P. K. Sinha, P. K. Dubey and S. Singh, "Identifying Tracheomalacia,” British Journal of Anaesthesia, Vol. 84, No. 1, 2000, pp. 127-128.

[15] K. Moaz, R. A. Greatorex and J. G. Allen, "Identifying Tracheomalaciaan Alternative Approach,” British Journal of Anaesthesia, Vol. 85, No. 2, 2000, pp. 332-333.

[16] F. F. Palazzo, J. G. Allen and R. A. Greatorex, "Laryngeal Mask Airway and the Fibre-Optic Tracheal Inspection in Thyroid Surgery: A Method for Timely Identification of Tracheomalacia Requiring Tracheostomy,” Annals of The Royal College of Surgeons of England, Vol. 82, No. 2, 2000, pp. 141-142.

[17] B. Cady, "Management of Tracheal Obstruction from Thyroid Disease,” World Journal of Surgery, Vol. 6, No. 
6, 1982, pp. 696-701. doi:10.1111/j.1445-2197.1987.tb01360.x

[18] E. M. ElBashier, A. B. Hassan Widtalla and M. ElMakki Ahmed, "Tracheostomy with Thyroidectomy: Indications, Management and Outcome: A Prospective Study,” International Journal of Surgery, Vol. 6, No. 2, 2008, pp. 147-150. doi:10.1016/j.ijsu.2008.01.010

[19] N. O. Machado, C. S. Grant, A. K. Sharma, H. A. AlSabi and S. V. Koliyadan, "Large Posterior Mediastinal Re- trosternal Goiter Managed by Transcervical and Lateral Thorocotomy Approach," General Thoracic and Cardiovascular Surgery, Vol. 59, No. 7, 2011, pp. 507-511. doi:10.1007/s11748-010-0712-X

[20] Q. Liu, G. Djuricin and R. A. Prinz, “Total Thyroidectomy for Benign Thyroid Disease,” Surgery, Vol. 123, No. 1, 1998, pp. 2-7. doi:10.1016/S0039-6060(98)70221-1 